\title{
CONTROLLING THE DELIVERING OF PROJECTS IN MEGA-EVENTS: AN APPLICATION ON EXPO 2015
}

\author{
GIORGIO LOCATELLI* AND MAURO MANCINI $\dagger$ \\ *School of Engineering, University of Lincoln, Brayford Pool, Lincoln, UK \\ †Department of Management, Economics \& Industrial Engineering, Politecnico di Milano, Milano, Italy
}

\begin{abstract}
The preparation of mega-events like Olympic Games, music festivals, or world expositions requires the successful and timely delivering of many correlated projects: buildings, ICT infrastructure, marketing projects, etc. The international market is increasingly characterized by large and mega-events. The size of these events escalates the complexity of management, often causing budget overruns and scope reduction. As a consequence it is fundamental to effectively monitor the progress of the entire program to react in case the progress does not follow the expected baseline. Project-controlling methodologies are well analyzed in the literature with respect to individual projects. For that which concerns the overall delivery of correlated projects (i.e., a program) the literature provides strategic and operational guidelines; however, far too little attention has been paid to developing quantitative methodology to control their execution phase. The purpose of this article is to review recent research into event planning and program management to propose a quantitative approach, based on the Petri nets and dynamic systems, to obtain the project envelope, a fundamental tool to assess and manage the progress of a program. The methodology is implemented on a real case study: EXPO 2015.
\end{abstract}

Key words: Mega-events; Universal EXPOsitions; Program; Controlling; Project envelope; Petri nets; Megaproject

\section{Introduction}

A recent article (Getz, 2012) asserts that there is a "recent growth in the numbers, size, cost, and impacts of festivals and events" (p. 171) and new tools and guidelines are required to deliver events regarding scope and budget. A common aspect among the mega-events is the necessity of delivering a large number of projects from different sectors (e.g., buildings, communication plans, ICT, infrastructure, etc.) that are connected by physical or logical links. An appropriated description of the challenges involved in planning and controlling the projects required by mega-events (in this case 
the 2004 Athens Olympic Games) is presented by Singh and $\mathrm{Hu}$ (2008). The authors stress the importance of considering different dimensions (i.e., types of projects) such as infrastructure, television rights, accommodations, media services, accreditation, cleanliness, security, technology, ticketing, food and beverage services, and transportation. This mix of projects is similar in many events such as festivals, Olympics, world fairs, World Cup, etc. In these mega-events each project is connected to other projects (e.g., a road is required before the pavilions can be built or the conclusions of a project trigger the beginning of another one).

A common practice in event preparation is the assignment of projects to several different subcontractors to exploit specific know-how and reduce cost. However, the higher the project's complexity and heterogeneity, the higher the difficulty for the main sponsor to control the overall progress (Van Marrewijk, 2005). As large projects and megaevents are often affected by overbudgets, delays, and benefit reduction (Flyvbjerg, 2006), it is necessary to employ an efficient progress control. This enables the prompt identification of issues and appropriate countermeasures to achieve the projects' goals. In particular, several "event management authors" have emphasized the need for more formal approaches to event planning (Moscardo, 2007). In particular Silvers, Bowdin, O’Toole, and Nelson (2006) show how we need project management tools specific to event management.

Because the literature does not provide clear guidelines or models for project control in megaevents, this article aims to fill that gap, providing a controlling methodology that can be used as an early warning system to assure the proper development of mega-events, detecting any deviation from the original schedule and allowing prompt management of critical situations.

Although suitable for several mega-events this model is implemented and tested using EXPO 2015. EXPO 2015 (the next scheduled Universal EXPOsition, hosted by Milan, Italy in 2015) is an emblematic example of this complexity. The undertaking of a universal exposition requires the realization of a large number of projects concerning different areas, such as construction, communication, advertising, and ICT infrastructures, with the involvement of many partners and stakeholders and a time frame of several years.

\section{Literature Review}

\section{Managerial Implications of Mega-Events}

Bramwell's article (1997) is a seminal work concerning the planning of mega-events. Focusing on the Sheffield 1991 World Student Games the author derives useful lessons. Two of them-“Too limited use of formal strategic planning may hinder decision-making” (p. 173) and in particular "A megaevent should be integrated with broad development planning” (p. 175) - are the focus of this article. In more recent years, there has been an increasing amount of literature on mega-events. Mega-events are usually characterized by a biased cost-benefits analysis: Locatelli and Mancini (2010) investigate the risk of optimistic overestimation of attendance in mega-events during the planning phase, and Mills and Rosentraub (2013) enlarge the analysis assessing the economic development effects of hosting mega-events.

Mega-events are characterized by several interrelated subprojects, which have to be completed within a deadline. As a consequence, under the classical management perspective, these events are classifiable as large programs. Indeed, Shehu and Akintoye (2009) define a program as "an integrated, structuredframework that coordinates, aligns and allocates resources, plans, executes and manages a number of related projects to achieve optimum benefits that cannot be realized if the projects were managed separately” (p. 704). Olympic Games, a large festival, or a universal exposition doubtless copes with this definition: it is formed by a series of projects that should be planned, executed, and managed appropriately in order to reach the deadline established. All these subprojects are strongly linked because of physical, logistic, and managerial constraints and that if one of them is not accomplished the whole success of the event could be affected. Finally, they are managed all together by a structured organization.

Mega-events require a large amount of resources and have lasting impacts; therefore, sustainability issues should be a priority in the manager agenda (Hall, 2012). Hede (2007) focuses on the sustainability 
dimension of planning special events providing a framework called triple bottom line. Hall (2012) combines the sustainability dimensions, tailoring them on mega-events: "In the case of mega-events, many normal policy and planning practices are abandoned" (p. 125). Considering the local population, Boo, Wang, and Yu (2011) present a framework outlining how involvement, community attachment, perceived benefits/cost, and perceived preparedness interact. They applied the framework to the Beijing 2008 Olympic Games. According to Preuss (2009), "Economic analysis of large-sport events usually focus on the positive effects and legacies while ignoring opportunity cost and the efficiency of using scarce resources" (p. 131); the condition for mega-events is not different. The only way to deliver sustainable events is careful planning and an even more careful controlling.

In general, project control methods are deeply documented in standard project management literature and the bigger the project, the more important is control because complexity and project dimension heavily affect manageability (Van Marrewijk, 2005). Under a project management point of view, mega-events are rather differentiated from typical engineering projects (like a bridge or a power plant), as their final output is formed by the realization of many different projects, involving public bodies and characterized by a mandatory deadline (Inauguration day) that has to be respected (Getz, 1997; Hiller, 2000). Scope modification and changes to in the plan are typical of mega-events, as in the case of Sochi 2014 (Prudnikova, 2012). In the case of delays, the normal alternatives are scope reduction or/and budget increase (to increase the resources), losing the focus on the sustainability dimensions. Therefore, one of the key aspects to deliver a sustainable large event is to recognize the delay as soon as possible and react accordingly.

The literature does not provide methods focused on mega-events or programs to control their progress. Therefore, the goal of the next section is to present the core literature relevant for developing a methodology suitable for controlling projects in mega-events.

\section{Controlling a Program}

Concerning programs and their management, Stretton (2010) reports the shortage of specific literature about managing multiple projects simultaneously. Traditional control mechanisms (such as Work Breakdown Structure, Gantt Charts, PERT/ CPM networks, Project Crashing Analysis, Tradeoff Analysis, etc.) are not entirely adequate for managing complex projects (Love, Holt, Shen, \& Irani, 2002). Moreover World Expositions or Olympic Games belong to a particular category of large projects, which both Guala (2002) and Roche (2000) identify with the term mega events or mega-events.

Usually scholars deal with topics and solutions more suitable for large projects characterized by technical complexity (De Bruijn \& Leijten, 2008), requiring strong synergies between partners and shared decision-making processes (Van Marrewijk, 2005). Attention is paid to social complexity of the environment where these projects are undertaken, concerning the particular roles (Flyvbjerg, 2007) and duties (Short \& Kopp, 2005) of public bodies. These peculiarities, however, fit large infrastructure projects (Van Wee, 2007) rather than mega-events where the complexity comes from the organizational dimension rather than the technical dimension (such as in a nuclear power plant or a long bridge). In fact, here subcontractors are established through several calls for tender by the Organizing Committee and the limited technical complexity of subprojects does not require strong synergies or shared decision-making processes. Nevertheless, the different projects (performed by different subcontractors) are linked by physical, logical, and managerial constrains. Complexity, therefore, is due to the management of the large number of partners involved (Ruuska, Ahola, Artto, Locatelli, \& Mancini, 2011) rather than the technical undertakings and knowledge sharing, where instead "megaprojects” literature focuses (Locatelli \& Mancini, 2012). In addition, guidelines on control aspects are too qualitative and limited to general suggestions. On the other hand, literature dealing properly with mega-events focuses on strategic problems such as urban development and post EXPO legacy (Hay \& Cashman, 2008), relationships between stakeholders or political factors (Roche, 2000). The main sponsors give scarce attention to control, focusing mainly on economic plans strategies, future cash flows, and operations (Linden \& Creighton, 2008). 
Given the specific relevance of the topic the UK Office of Government Commerce (OGC, 2007) provides two relevant but qualitative guidelines:

Managing a programme does not mean micromanagement of the projects within it. Communicating the right information (originated from the level of detail) between the programme and its projects is a major consideration when establishing programme control. (p. 96)

Projects should be empowered but need clear tolerance and limits to ensure they do not exceed their delegated authority. Allowing the project managers to manage their projects within the tolerances set by the programme in an essential part of good programme management. (p. 96)

These guidelines tackle the typical issue of excessive hierarchical bureaucracy and control. It is difficult to achieve an appropriate balance between excessive control and insufficient control in a multiproject context. Standard approaches to program management tend towards excessive control (OGC, 2007). Lycett, Rassau, and Danson (2004) argue that excessive bureaucracy and control create inflexibility, bureaucratic overheads of reporting requirements, and, in extreme circumstances, relegate the program management to little more than a mechanism for reporting. The negative consequences of an overly bureaucratic approach to program management are both a deterioration of the relationship between project managers and program managers encouraging a culture of blame.

A related issue is the focus on an inappropriate level of detail. Because of program dimension, large integrated plans/networks are difficult to formulate and have a tendency to become excessively complex as in project management techniques aimed to control every last detail of individual subprojects (Lycett et al., 2004; Pelleginelli \& Patrington, 2006). This approach should be absolutely avoided (Aritua, Smith, \& Bower, 2009). On the other hand, Nieminen and Lehtonen (2008) report how focusing on the program as a whole, without paying attention to the subprojects, could lead to an inappropriate monitoring, with the consequence of not being able to intervene promptly in case of issues. By focusing at an inappropriate level of detail, there is a real risk that program managers will fail to identify the critical success factors for that program. Consequently, the focus at the program level should be on the interfaces between projects (Levene \& Braganza, 1996). This approach gives flexibility to project managers in charge to realize subprojects and at the same time maintain the necessary level of control and accountability (Aritua et al., 2009). Moreover, Levene and Braganza (1996) suggest an approach structured around key milestones in subprojects, where each milestone should be placed on the interfaces between projects.

Regarding lessons learned from past events, Lycett et al. (2004) presents two main reasons for the poor performance of large programs.

\section{Program management is a scaled-up version of} project management (as presented also by Levene \& Braganza, 1996; Pelleginelli \& Patrington, 2006). Program managers consider that programs, projects, subprojects, and work packages are simply different levels in a hierarchy of project type work activities. As a consequence program managers focus on a level of detail that can lead to a negative spiral of bureaucracy and control, losing focus on the macrogoals the program has to achieve.

2. "One-size-fits-all” approach to program management. There is a common perception that organizations should apply a standard approach for the management of all projects in a program, regardless of project type, size, urgency, or the type of resource used (Payne \& Turner, 1999). The presumed benefits of this approach include comparable progress reporting and the possibility for people to move freely between projects without having to learn a new approach. However, better results are achieved at a project level when people tailor procedures to the type of project that they are working on (Payne \& Turner, 1999). Extending this logic to the engagement between the projects and programs, it is likely that different types of project will benefit from different program management approaches.

Payne and Turner (1999) suggest that different types of projects require a different approach of controlling, in particular:

- Type 1-Engineering projects: When detailed planning is not possible, authors suggest a 
milestone-based approach, where the milestones are components of the final output.

- Type 2-Product development projects: Planning and controlling should be based on a Bill of Materials (or Product Breakdown Structure; PBS). This is a milestone-based approach where the milestones represent components of the final product.

- Type 3-IT Systems: Because the goals are usually poorly defined, the planning and controlling approach tends to be structured around a project's life cycle, namely a milestone-based approach where the milestones here represent completion of life-cycle stages (as programming, computing, testing, and other typical phases of IT systems development).

- Type 4-Research and organizational changes: These projects are characterized by goals that are not well defined and methods that depend on the situation, making it very difficult to formulate a detailed activity plan. The best method is a milestone-based approach, where projects tend to be managed through life cycle stages or the achievement of crucial steps.

In conclusion, a successful control of programs does not require complex scheduling and monitoring of individual projects but the level of detail should focus on the interface between subprojects or their key milestones. These guidelines have been widely adopted in the development of our methodology.

\section{Methodology}

Considering the background presented in the previous sections, we aim to describe and apply a suitable methodology to control the projects required in mega-events.

\section{Program Work Breakdown Structure}

The first step in order to manage efficiently a huge program is the hierarchical disaggregation of the projects involved. It is necessary to create a hierarchical subdivision, as the Work Breakdown Structure (WBS) in projects, but able to fit the size of programs. This solution, called Program Work Breakdown Structure (P-WBS) and presented by
Ipsilandis, Sirakoulis, Polyzos, and Gerogiannis (2004), allows a first disaggregation of the program and a separate analysis of projects in selected macroareas. Mavrotas, Caloghirou, and Koune (2005) suggest a division based on Program $\rightarrow$ Axis $\rightarrow$ Measures $^{1} \rightarrow$ Projects $\rightarrow$ Contracts. The contract level is the most specific level of detail adopted as suggested also by Turner (2009). At the first level the program is divided into subgroups ("Axes") of homogeneous projects; each Axis is subsequently divided into "Measures," which classify in a more specific way the projects in the program. This is a second level of grouping, and in general it depends on the number of projects that have to be realized. Because of EXPO 2015's size, it is necessary to introduce a further layer of subdivision, named "Cluster." Every Cluster contains from a few to dozens of projects that will be assigned through separate contracts (deriving from different calls for tender) to subcontractors. Each project may have one or more involved contracts, thus it will be subdivided into subprojects in order to have a one to one correspondence of subprojects to contracts. Figure 1 shows the cited subdivision for EXPO 2015. Because of space constraints, Axes and Measures have been reported for the whole program, whereas Clusters, Projects, and Contracts have been limited to a particular branch.

\section{Milestone Plan}

In a mega-event each contract is signed between the company in charge to manage the event (in EXPO 2015 the EXPO 2015 S.p.A) and single subcontractors. Usually in this kind of contract the payments are executed when the subcontractor achieves certain milestones. Subsequently, from the point of view of the Organizing Committee, it is possible and relatively easy to outline the progress of a project by its milestone plan (Turner, 2009), delegating the details of a more accurate scheduling to subcontractors. It is neither possible nor advisable to use economic expenses to monitor the status of a subproject as suggested in Mavrotas et al. (2005). First, mega-events have a mandatory deadline and therefore time assumes priority above costs (Mazzeo, 2008); second, there is not the complete assurance that all contracts will be lump sum. Hence, it will be necessary to "downgrade" the level of reporting by 


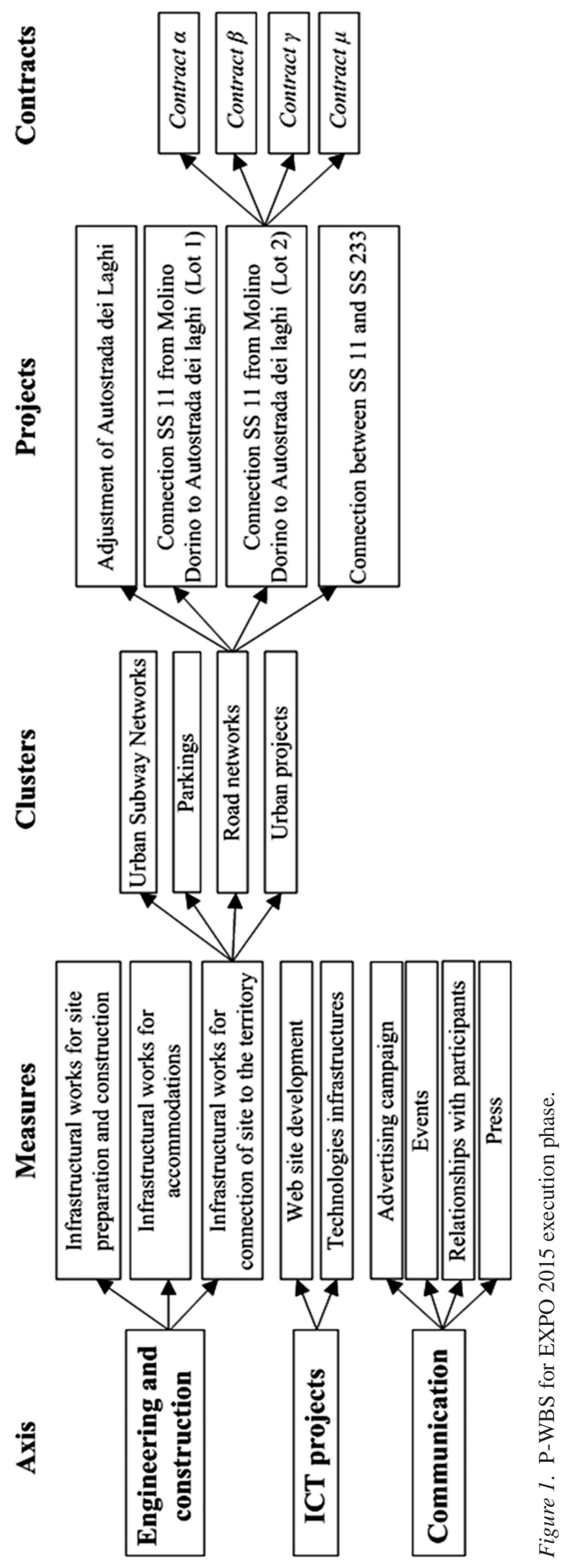

analyzing directly its physical progress. Levene and Braganza (1996) and Lycett et al. (2004) report that, in these cases, the control through milestones is the most reasonable solution. Aritua et al. (2009) show that in mega-events the "milestone plan" is the right balance between allowing flexibility and maintaining the necessary level of control and accountability. Moreover, planning through milestones forces the organization to use a results-oriented approach. This is more appropriate for large projects than an activity-based approach whose level of detail would be neither practical nor useful to manage (Andersen, 1996). This solution is also aligned with legislation of several countries (including the Italian law for EXPO 2015) dealing with projects involving public bodies (Boso, 2006), where usually the progress is monitored through IPC ${ }^{2}$.

\section{Subproject Envelope}

Standard project management techniques assert that it is possible to achieve a significant idea of project status by comparing when a milestone has been achieved with respect to the baseline program (Andersen, 1996). We start from this proven method, proposing a scheduling of subprojects based on different milestone curves. The first step is to show the dependencies between milestones belonging to different subprojects within the program, creating the "program result path" as shown in Figure 2. Commercial software based on Petri Nets (see the Appendix) like “Arena Simulation Software” by "Rockwell Automation" is commonly adopted to cope with these types of networks.

It is now possible to schedule the milestones as a common Activities-on-Arrows network (Maylor, 2004). Each intermilestone lag is scheduled three times, one for each scenario, namely: early, standard, and late. Each scenario represents the expected outcome of a certain strategy. The reasonable assumption is that if longer time is required for the earlier milestones (late scheduling) the latter have to be faster (using corrective actions such as double shifts) because of the fixed deadline. Specific progress is earned according to milestone achievement and each contract is scheduled according to the result path. In this way it is possible to create an early curve, which foresees a consistent amount of progress in early phases, whose pace will decrease 


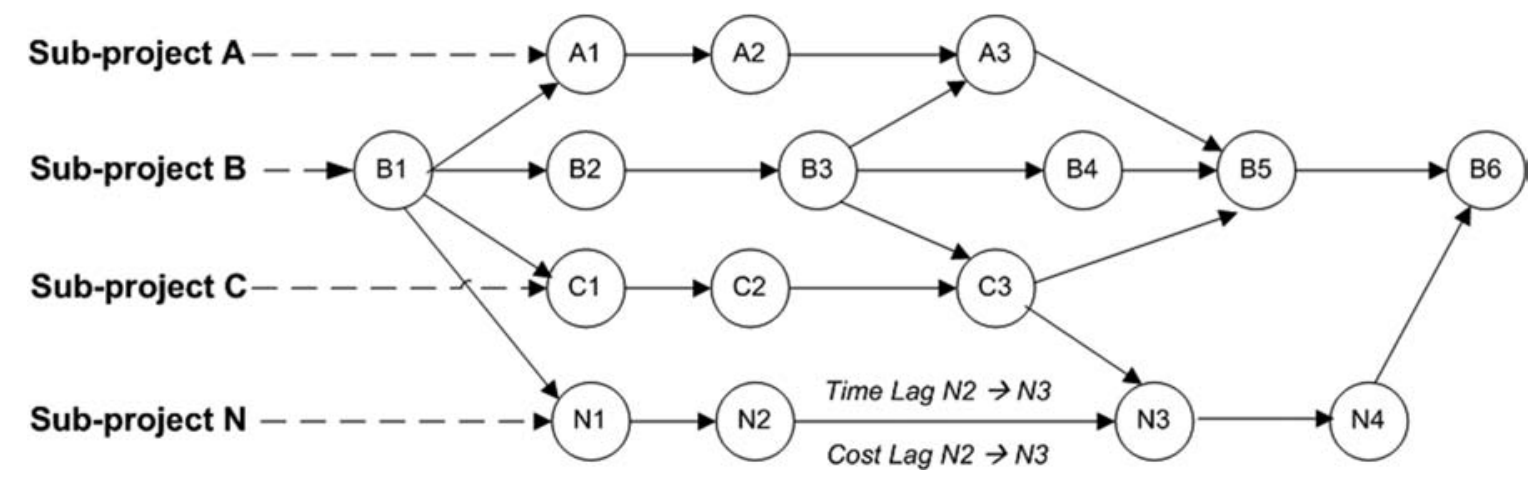

Figure 2. Program result path.

later on; a standard curve, which foresees a most likely time lag to reach the milestones, with homogeneous effort spread over project phases; and finally a late curve, which foresees a longer time to reach the early milestones, but which will progress much faster in the later phases. Each curve will be standardized between 0 and 1 to compare subprojects (Figs. 3 and 4). The (eventual) crossing of the three curves creates an envelope (Fig. 5), which should identify the zones within which the subproject is running correctly. Where the subproject moves outside the envelope, it may be considered to be either late or surprisingly ahead of schedule.

This envelope reduces the necessity to operate perfect forecasts about duration, critical in projects or programs of big dimensions (Lycett et al.,
2004). Intermilestone lags are not deterministic values and statistical fluctuations are a normal part of any task execution (Kendall \& Rollins, 2003). Moreover, if detailed and precise forecasts are very difficult even for a single project (Andersen, 1996), this task becomes critical in a huge program typical of mega-events. The envelope overcomes the inevitable inaccuracy of a single forecast, as it use upper and lower bounds instead of a specific function (Mavrotas et al., 2005).

The subproject envelope permits the creation of a monitoring system based on project statuses, identified according to the relationship between actual milestones and the envelope, as Table 1 reports.

The limit between the green and orange zones is a management decision: for instance, when curves

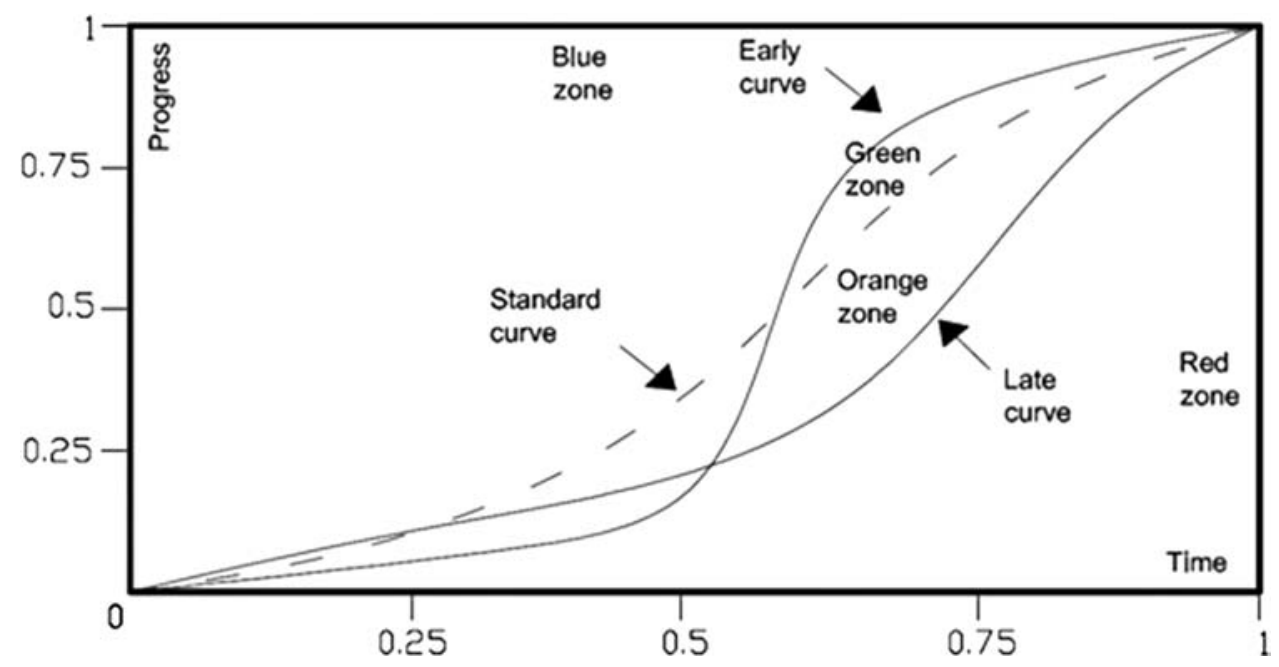

Figure 3. Contract A. 


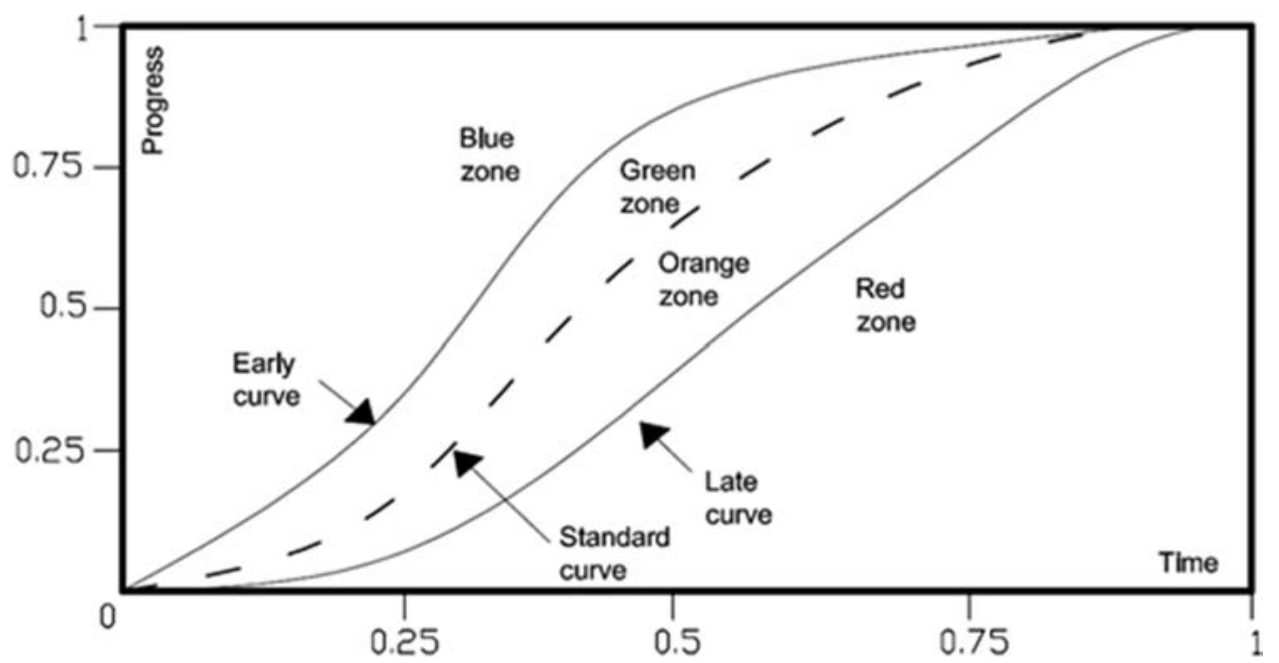

Figure 4. Contract C.

do not cross (Fig. 4) this bound may be the standard curve; when crossing (Fig. 3) this bound may be a selected curve between the upper and lower bounds. The green zone does not identify the ideal position where contracts should run. These statuses prescribe correct control reactions according to contract progress. Ideally the most advantageous strategy for the Organizing Committee is when a contract runs as close as possible to the lower bound, postponing the payments but still respecting the deadline. On the other hand, although it is economically advantageous, this strategy jeopardizes the subprojects and therefore requires more tightly controlled rules (orange status). Given the status, corrective actions are part of a good risk management. However, in this way each contract in the program can be monitored with gradual control, with a level of detail tailored on its status. This approach is flexible and open to contingent adjustment during its execution as advocated by Lycett et al. (2004). Furthermore, Kendall and Rollins (2003) assert that in project control, it is necessary

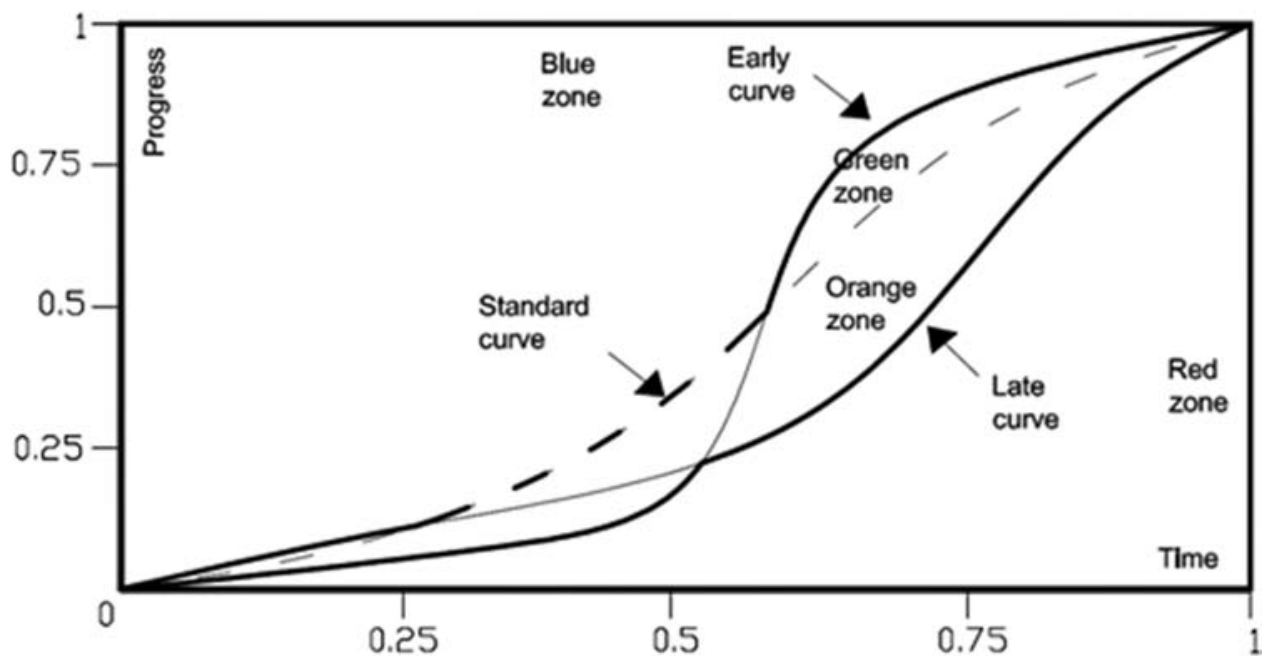

Figure 5. Contract B and subproject envelope. 
Table 1

Envelope and Project Statuses

\begin{tabular}{ll}
\hline Status & \multicolumn{1}{c}{ Meaning } \\
\hline Green zone & $\begin{array}{l}\text { Last actual milestone falls close to the upper bound, thus there are no current problems and no need for further } \\
\text { investigations: the Organizing Committee will attend the next milestone check. } \\
\text { Last actual milestone falls close to the lower bound, but still inside the envelope. This situation requires further } \\
\text { investigation and preventive contingency plans, such as shorten the time formal reports are produced in order } \\
\text { to check the progress more carefully. } \\
\text { Last actual milestone falls under the lower bound. The contract is running late and the deadline can be reached } \\
\text { just with extraordinary corrective actions. Solutions are changing the subcontractor (when possible), allocate } \\
\text { more resources through specific recovery plans (i.e., increase work up to 24 hours a day), or in the worst case } \\
\text { reducing subproject scope. } \\
\text { Considering EXPO structure, another situation that should be investigated is when actual milestones fall over } \\
\text { the upper bound. This means that the contract is running faster than optimistic expectations, therefore it is } \\
\text { necessary to check if the work is performed as required. }\end{array}$ \\
\hline
\end{tabular}

to eliminate demotivating measurements. Statistical fluctuations are a normal part of any task execution on a project, so the system must allow individual tasks to exceed estimates without implying a new planning. Where a single curve predicts (perhaps mistakenly) delayed development of a project, the project team will be affected psychologically and may precipitously commence corrective actions or scope reduction. With the envelope, issues are split twofold: red status, which requires corrective actions, and orange, which does not necessarily requires big changes, allowing some delay with the chance to recover, guaranteeing flexibility and not increasing excessively the pressure on the team.

\section{Program Aggregation}

Contracts are related to specific Axes (Table 1), and each of them concerns a different project type (Fig. 2). Payne and Turner (1999) suggest that the importance of milestones (or their weights) should be tailored to the subproject peculiarities, as a unique method to evaluate them may cause misleading measurements. For these reasons, different types of contracts will be planned and controlled in different methods. Table 2 reports reasonable measures for the different type of axes. To keep the model very practical it is possible to assume a progress of either $0 \%$ or $100 \%$ (i.e., the progress is $0 \%$ until the milestone is reached, then it is $100 \%$ of

Table 2

Guidelines to Weight the Different Milestones in Different Types of Projects

\begin{tabular}{|c|c|c|c|}
\hline Axis & Measures & Milestones & \% Progress \\
\hline $\begin{array}{l}\text { Engineering } \\
\text { and construction }\end{array}$ & $\begin{array}{l}\text { Infrastructural works for site } \\
\text { preparation and construction } \\
\text { Infrastructural works for } \\
\text { connection of site to the territory } \\
\text { Infrastructural works for } \\
\text { accommodations }\end{array}$ & $\begin{array}{l}\text { Output components } \\
\text { or phases }\end{array}$ & $\left(\right.$ Time laga $\left.M_{i} \rightarrow M_{i-1}\right) / \sum_{i}\left(\text { Time lag } M_{i} \rightarrow M_{i-1}\right)^{\mathrm{b}}$ \\
\hline ICT projects & $\begin{array}{l}\text { Technologies infrastructures } \\
\text { Website development }\end{array}$ & Life cycle stages & $\left(\right.$ Time lag $\left.{ }^{\mathrm{a}} M_{i} \rightarrow M_{i-1}\right) / \sum_{i}\left(\text { Time lag } M_{i} \rightarrow M_{i-1}\right)^{\mathrm{b}}$ \\
\hline Communication & $\begin{array}{l}\text { Event } \\
\text { Press } \\
\text { Advertising campaign } \\
\text { Relationships with participants }\end{array}$ & $\begin{array}{l}\text { Each event } \\
\text { EXPO stages } \\
\text { Campaign phases } \\
\text { Relation phases }\end{array}$ & $\begin{array}{l}\left(\text { Cost lag } M_{i} \rightarrow M_{i-1}\right) / \sum_{i}\left(\text { Cost lag } M_{i} \rightarrow M_{i-1}\right)^{c} \\
\text { Level of effort } \\
\left(\text { Cost lag } M_{i} \rightarrow M_{i-1}\right) / \sum_{i}\left(\text { Cost lag } M_{i} \rightarrow M_{i-1}\right)^{c} \\
\text { Conventional \% }\end{array}$ \\
\hline
\end{tabular}

Note: $M$ is milestone and $i$ is milestone of the specific contract.

${ }^{a}$ Achieving a milestone will earn the estimated standard time lag.

${ }^{\mathrm{b}} \sum_{i}$ (Time lag $M_{i} \rightarrow M_{i-1}$ ) is the total number of standard work hours (standard scheduling) foreseen in the contract.

${ }^{c} \sum_{i}^{i}\left(\right.$ Cost lag $\left.M_{i} \rightarrow M_{i-1}^{i-1}\right)$ is the total cost foreseen for the contract. 
the weight of such milestone). If there is more reliable information, it is possible to provide a more accurate measure.

So far the article has focused on how to monitor the progress at project level; the next task is to compute the progress at program level (i.e., event level). In this case, Payne and Turner (1999) suggest that a single method has to be found to evaluate the overall progress. Considering the typical subprojects in an event preparation is relatively easy to assign a percentage weight to contracts in the P-WBS. According to specific event features, these weights will be established by evaluating three different aspects: (a) economic importance of the contract, (b) risk (i.e., mainly probability and impact of a late delivery), and (c) strategic importance for event success. Weights will be identified by experts and by the Organizing Committee. The multiplication of weights with the respective WPs or projects provides the overall progress.

\section{Results: Application to EXPO 2015}

Milan EXPO 2015 is one of the largest Italian events (and programs) in the last decades. Because of its financial and temporal organizational dimensions (16 billion Euros and 10 years of planning (according to Comitato di Candidatura in 2006) it is definitely a large project (Altshuler \& Luberoff, 2003; Flyvbjerg, Bryzelius, \& Rothengatter, 2003). As a consequence the main typical risks are: cost overruns (Flyvbjerg, 2006) and time delays (Van Marrewijk, 2008).

\section{Project Envelope}

A simplified example of the Program Work Breakdown Structure (P-WBS) for EXPO 2015 was shown above. This section deals with a full scale P-WBS for EXPO 2015 and shows how the model is scalable to many different types of events. In order to simplify the explanation we assume that each subproject corresponds to a specific contract. This assumption is easily modifiable by adding new layers and modifying the P-WBS (e.g., giving the execution of the building structure to a specific subcontractor and the development of services plants to another one). After the creation of the P-WBS, it is necessary to identify the program result path reporting the milestone plan for all subprojects involved and showing their interdependencies.

The information required comes from the 2006 Dossier di candidatura per Expo Milano 2015 by Comitato di Candidatura:

a) The official master-plan 2010 reporting the construction projects required to realize the EXPO 2015 site and their temporal constraints.

b) Candidacy documents reporting the temporal development of other projects involved in EXPO, such as the ICT sector and the Communication plan (advertising campaign and relationships with participants).

c) Milestone identification, milestone durations, dependencies between subprojects, and contracts weights have been created from expert elicitation providing an exhaustive example of how the model works.

Considering the P-WBS, the result path has been created starting from the EXPO Gantt chart. Each subproject has been divided into a set of milestones. Temporal and logical constraints have been identified with the precedence diagram; the subproject durations reported in the master-plan and in the candidacy documents have been considered as "standard forecast." To simplify the reporting process, it has been assumed that the end of a milestone triggers the beginning of the next one; however, the lags can be easily introduced as dummy activities.

In order to create the project envelope a triangular distribution has been set for every process (intermilestone lag) in the system. The "distribution skewed towards optimistic estimate" (Hendrickson, 1998) has been taken into consideration when defining this distribution. According to it, it is more likely to be late than ahead of time. This choice has been made in order to create a wider orange zone in the envelope (the medium bound will be closer to the upper bound) and having an earlier level of alarm during the execution of the subprojects. After executing the simulation ${ }^{3}$, the software records, in a .txt file, all the milestone achievement times.

The last step, in order to create the progress curve, is the definition of milestone weights, which as mentioned are different depending on contract typology. Having assigned the milestone weights to the contracts, it is possible to create the scatterplot, 
which identifies the subproject envelope (Fig. 6). Now it is possible to connect the earliest, latest, and average dates for each progress to create the project envelope (Fig. 7).

\section{Program Envelope}

The same methodology used for a single contract can be applied also to establish the envelope for the overall program. Because of the presence of different project typologies it is necessary to insert the weights for every contract involved in the program. In order to rationalize the assignment of contracts weighting, it is possible to adopt the representation of the P-WBS shown in Figure 8.

Step 1: Axes Weight. Axes have been assigned with a weight proportional to the importance of their elements for the event success. Engineering and Construction projects have been identified as the most important elements (50\%), as the realization of the event site is surely the final and most visible outcome of an EXPO. Communication projects (35\%) are also strategic for event success as they provide visibility for current and future participants, significantly influencing the financial results of the event. Finally, ICT projects, although important, have been given
$15 \%$, as they have been considered less strategic than the other axes. As stated by Papagiannopoulos, Xenikos, and Vouddas (2009) "the ICT network construction is subject to management choice rather than technological imperative” (p. 115).

For engineering and construction subprojects milestone lags are weighted depending on their work content. Achieving a milestone earns a percentage progress corresponding to the ratio between intermilestone lag and work content (identified by summing up all intermilestone lag standard durations). Communication projects belong to the "communication axis" and therefore require a different method to establish the weights of their milestones (see Fig. 8, as Contract V and U). For Contract V (relationship with participants, Fig. 8) weights have been assigned considering a conventional percentage related to the importance of relationship phase. For Contract $\mathrm{U}$ (advertising campaign, Fig. 8) it was decided to assign milestone importance according to the budget spent in that lag. For ICT projects, as for construction, it was decided to weight these contracts according to the ratio between standard duration of milestone lags and overall work content of the contract.

Step 2: Contract Importance. Different projects have different importance for the organization of

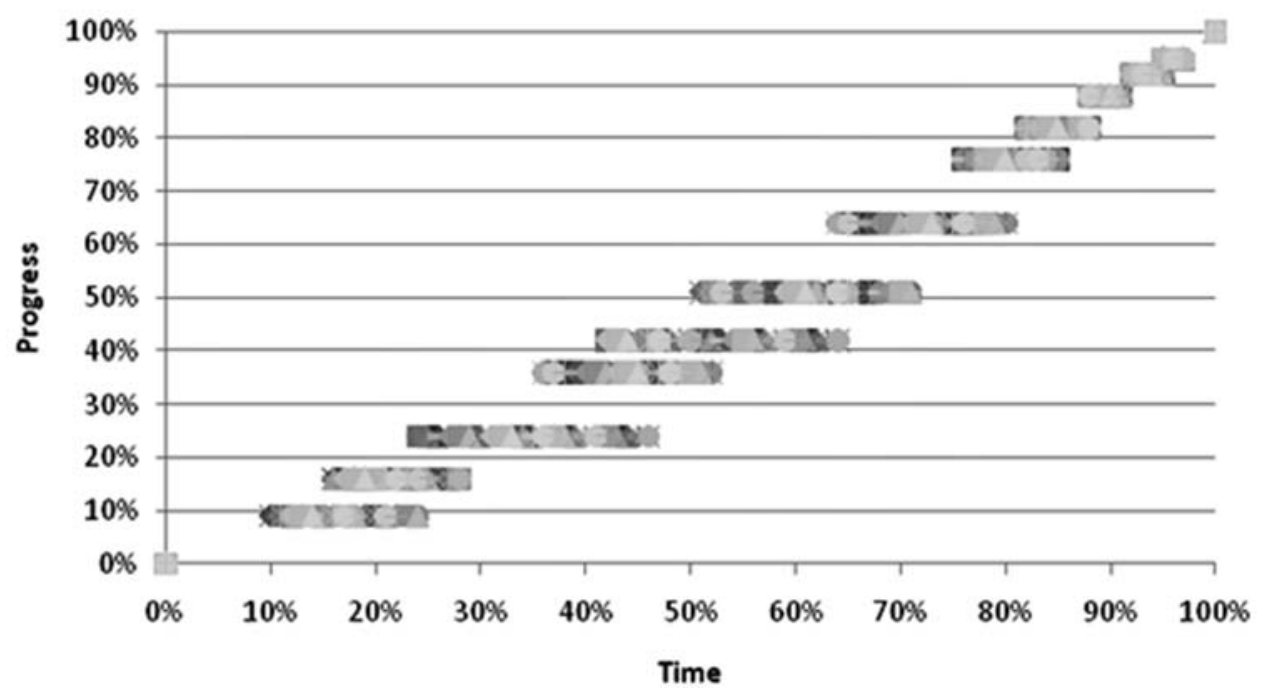

Figure 6. Scatterplot for Contract P. This figures shows when the milestones are achieved. Because the milestones are always the same for all the simulations, but are achieved at different times, the progress is always the same, but the time is different. 


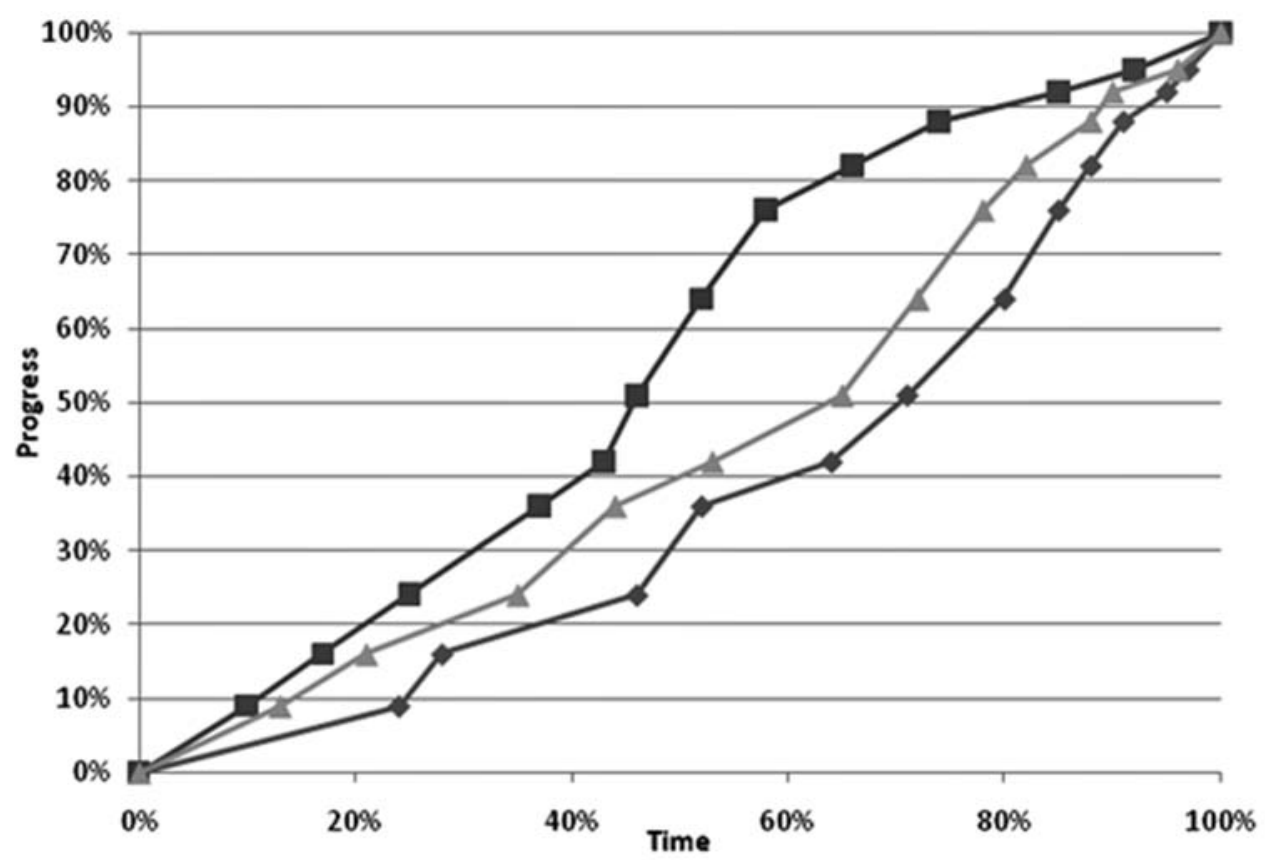

$\rightarrow$ lower bound $\quad \rightarrow$-upper bound $\quad \rightarrow$ medium bound

Figure 7. Project envelope for Contract P.

EXPO 2015; therefore, contract in the same axis has been weighted according to drivers identified in Table 2, namely strategic and economic importance and risk of not respecting deadlines. For instance, Contract A (site preparation, 20\%) is fundamental in order to allow the realization of all the buildings in the EXPO site. Delays in this phase will postpone all the other projects with a high risk of missing the final deadlines. Otherwise, subproject V $(60 \%)$ is fundamental for the involvement of institutional and corporate participants: the signing of the formal contract (land acquisition for the pavilion or sponsorship) helps to gather funds that can be used to finance other projects (economic importance). Finally, the construction of national and corporate pavilions has been assigned with just the $5 \%$, as this task is delegated directly to participants and therefore its fulfillment is not strategic (strategic importance) for the management. After the weights assignment, it is possible to run the method and create the overall envelope (Fig. 9), with the output of a scatterplot and final curves.

\section{Discussion and Conclusions}

The past years have seen increasing complexity and importance in the field of mega-events. As a consequence, one of the key success factors is careful preparation with the timely delivery of all the projects involved. The literature suggests that in mega-events the level of detail in the controlling phase should be focused on milestones within contracts and that each subproject should be analyzed with a specific method to determine appropriate milestones and to evaluate its progress. These solutions differ from the overcontrol and the "one-size-fits-all” approach that qualitative guidelines presents. The purpose of the current study was to determine a method to control the progress in the preparation of mega-events. The methods used here for EXPO 2015 may be applied to other mega-events elsewhere in the world. The result of the method (i.e., the project envelope) facilitates the issue of identifying perfect forecasts and, at the same time, gives the flexibility that a long-term project requires. 
Axis

Measure

Areas

Projects

Contracts
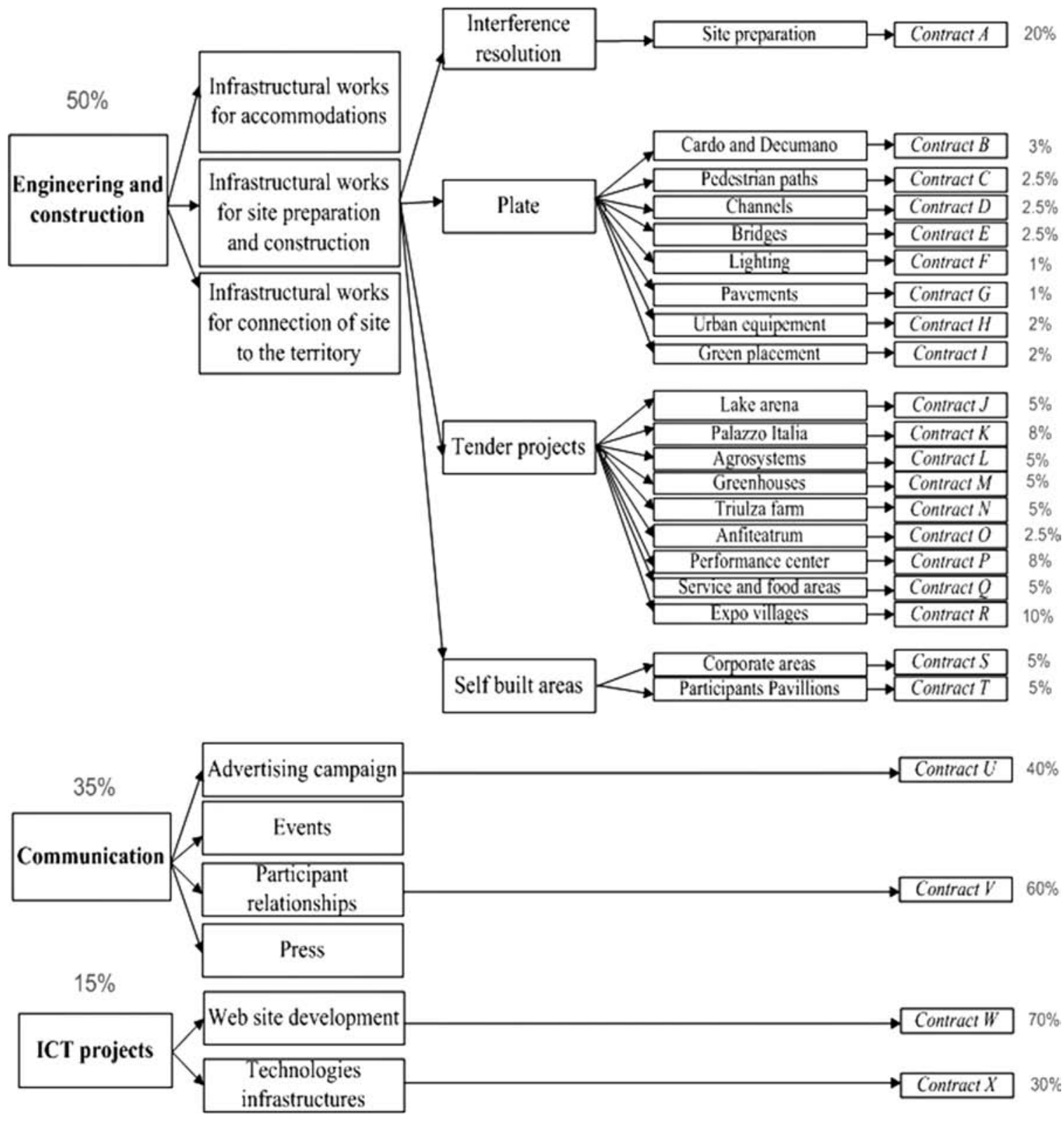

Figure 8. Weighted program work breakdown structure. 


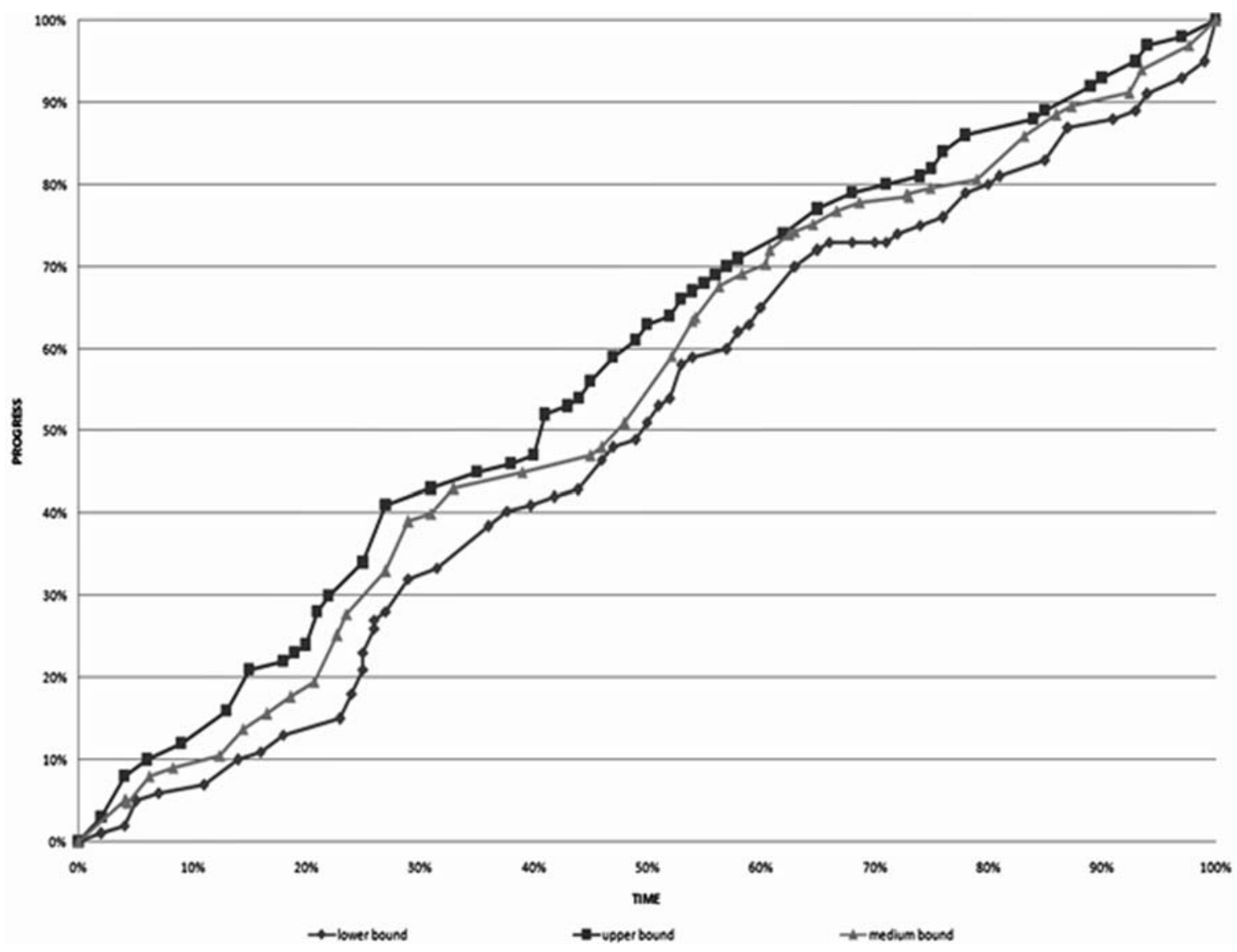

Figure 9. Final program envelope.

\section{Further Research}

It is recommended that further research be undertaken in the following five areas:

Legal aspects: The envelope is based on milestones and identifies three different curves (late, standard, and early). It should outline how this managerial format links with the local law concerning public projects. Because IPCs are the most common way of managing the projects, the setting of penalties and other legal procedures should be identified for subprojects that do not run as expected.

Real time controlling: This work has dealt with exante control methodologies. More broadly, research is also needed to determine the corrective actions that must be taken when actual values are available. Rescheduling activities in case of delays, corrective actions such as relaxing some constraints to the initial result path, or changing the subcontractor are just a sample of available options.

Criteria for scope reduction: Sometimes, typically because of overoptimistic initial estimates, it is not possible to meet the final deadline. A common countermeasure is to reduce the scope by eliminating nonessential projects. Nevertheless, there is no quantitative method to select which projects are deleted with respect to the time saving on the overall program. An improved version of this methodology might be able to provide this information.

Risk strategy: Even if the project manager can choose any possible strategy (i.e., curve) there is the classical trade-off between "earliest schedule" (e.g., less risk of delay, higher financial costs, scope creep, Parkinson's Law, etc.) and "late schedule" 
(e.g., high risk of delay, lower financial costs, etc.). This preliminary work assumes the same total cost and risk for each schedule; inclusion of other aspects of risk would be a further development.

Agile version: The methodology described in this article is very effective and accurate, but requires many hours for its implementation. This effort is more than justified for mega-events with budgets in the order of magnitude of hundred millions or billions of Euros, but is probably a bit cumbersome for smaller events. Further research might investigate how to derive a more agile version.

\section{Acknowledgment}

The authors are very grateful to Mr. Richard Allarton and the anonymous reviewer for their thoughtful comments. Those comments provided a great support for enhancing the quality of our paper.

\footnotetext{
Notes

${ }^{1}$ Axes and Measures are just conventional words used by some practitioners and (Mavrotas et al., 2005). They do not have a specific meaning and are simply the names of the different levels of the hierarchy.

${ }^{2}$ This acronym stands for "Interim Payment Certificate." The original Italian term is "Stato Avanzamento Lavori" (SAL) (Boso, 2006).

${ }^{3}$ Using a Pentium 4, CPU 3.00 GHz and 760 RAM MB the time needed to execute 100 simulations was 13 seconds.
}

\section{Appendix: Implementation of the Method Using Petri Nets}

The best way to approach the Petri Net (PN) theory and practice is by referring to Ferrarini (2001) and Murata (1989). Briefly, a PN is a net composed of places and transitions, which are connected through directed arcs. A place can be connected only to transitions and vice versa. The input places to a transition are the places at which an arc runs to it; its output places are those at which an arc runs from it. Input places to a transition $t$ are its preset identified by ${ }^{\circ} t$. Output places of a transition $t$ are its post set identified by $t$. Places may contain any number of tokens. Arcs can be associated with an integer representing the weight of the arc. A marking is a distribution of tokens over the places of a net.
A transition is enabled if all its input places have a number of tokens equal or greater to the weight of the arcs connecting the input places to the transition. When a transition is enabled, it can fire (i.e., execute), consuming from each input place a number of tokens equal to the weight of the arc connecting the place with the transition, and producing a number of tokens for each output place equal to the weight of the arc connecting the transition to the place. Execution of PNs is nondeterministic, because more than one transition can be enabled at the same time, but only one transition can fire at any moment and it is chosen in a nondeterministic way.

PN models can be used to analyze interdependencies, criticality, substitution, conflicting resource priorities, availability of resources, and variations in the availability of resources (Kumar \& Ganesh, 1998). PNs have been vastly used modeling and analyzing discrete event systems including manufacturing and communication processes. Although PNs possess very attractive modeling capabilities, their presence is almost nonexistent in the context of project program and event management. The system dynamics are assuming growing interest in project management: Rodrigues and Bowers (1996) report how in complex projects, interrelationships between activities are more complex than that suggested by the traditional work breakdown structure of project network. Recently, Cohen and Zwikael (2008) suggest a method for the project scheduling through PN. PNs permit the implementation of automatic time constraints assessment, the rescheduling when actual values are available (Del Foyo \& Silva, 2008), the "what if" analysis through simulations (Kumanan \& Raja, 2008), and the graphical representation of progress curves (Delgadillo \& Liano, 2007).

To proceed with the implementation of the model proposed in this article, Rockwell ARENA 13.0 software (based on the theory of Petri Nets) has been used to simulate the behavior of dynamic productive systems.

References

Altshuler, A., \& Luberoff, D. (2003). Mega projects: The changing of politics of urban public investment. Washington, DC: Brookings Institution. 
Andersen, E. (1996). Warning: Activity planning is hazardous to your project's health. International Journal of Project Management, 14(2), 89-94.

Aritua, B., Smith, N., \& Bower, D. (2009). Construction client multi-projects-A complex adaptive systems perspective. International Journal of Project Management, 27(1), 72-79.

Boo, S., Wang, Q., \& Yu, L. (2011). Residents' support of mega-events: A reexamination. Event Management, 15(3), 215-232.

Boso, A. (2006). Codice universale degli appalti pubblici (tomo III): Normativa generale e speciale, Modulistica, Schemi e Statistiche. Ancona, Italy: SIFIC.

Bramwell, B. (1997). Strategic planning before and after a mega-event. Tourism Management, 18(3), 167-176.

Cohen, Y., \& Zwikael, O. (2008). Modelling and scheduling projects using Petri nets. International Journal of Project Organisation and Management, 1(2), 221-233.

De Bruijn, H., \& Leijten, M. (2008). Management characteristics of mega projects. In B. Flyvbjerg, H. Premius, \& B. Van Wee (Eds.), Decision making in mega projects. Northampton, UK: Elgar Publishing Inc.

Del Foyo, P., \& Silva, J. (2008). Using time petri nets for modeling and verification of timed constraints workflow systems. ABCM Symposium Series in Mechatronics, 3, 471-478.

Delgadillo, G., \& Liano, S. (2007). Scheduling application using Petri nets. A case study: Intergrafas S.A. Paper presented at the 19th International Conference on Production Research, Valparaiso, Chile.

Ferrarini, L. (2001). Controllo logico con Reti di Petri. Bologna, Italy: Pitagora Editrice.

Flyvbjerg, B. (2006). From Nobel Prize to project management: Getting risk right. Project Management Institute, 37(3), 5-15.

Flyvbjerg, B. (2007). Truth and lies about megaprojects. Retrieved from http://flyvbjerg.plan.aau.dk/Publications 2007/InauguralTUD21PRINT72dpi.pdf

Flyvbjerg, B., Bryzelius, N., \& Rothengatter, W. (2003). Mega projects and risk: An anatomy of ambition. Cambridge: Cambridge University Press.

Getz, D. (1997). Event management and event toursim. New York: Cognizant.

Getz, D. (2012). Event studies: Discourses and future directions. Event Management, 16(2), 171-187.

Guala, C. (2002). Per una tipologia di mega eventi. Bollettino Società Geografica Italiana, VII(4).

Hall, M. C. (2012). Sustainable mega-events: Beyond the myth of balanced approaches to mega-event sustainability. Event Management, 16(2), 119-131.

Hay, A., \& Cashman, R. (2008). Connecting cities: Mega Event cities. Sydney: Sydney Olympic Park Authority for Metropolis Congress 2008.

Hede, A. M. (2007). Managing special events in the new era of the triple bottom line. Event Management, 11(1-2), 13-22.

Hendrickson, C. (1998). Project management for construction. Pittsburgh: Carnegie Mellon University.
Hiller, H. (2000). Mega-events, Urban boosterism and growth strategies: An analysis of the objectives and legitimations of the Cape Town 2004 Olympic bid. International Journal of Urban and Regional Research, 24(2), 449-458.

Ipsilandis, P. G., Sirakoulis, K., Polyzos, S., \& Gerogiannis, V. (2004, June). A DSS based methodology for programme management. In Proceedings of the International Project Management Association (IPMA)-World Congress on Project Management, International Project Management Association, Budapest.

Kendall, G., \& Rollins, S. (2003). Advanced project portfolio management and the PMO: Multiplying ROI at warp speed. Fort Lauderdale, FL: J. Ross Publishing.

Kumanan, S., \& Raja, K. (2008). Modeling and simulation of projects with Petri Nets. American Journal of Applied Sciences, 5(12), 1742-1749.

Kumar, A., \& Ganesh, L. S. (1998). Use of Petri nets for resource allocation in projects. Engineering Management, IEEE Transactions on Engineering Management, 45(1), 49-56.

Levene, R., \& Braganza, A. (1996). Controlling the work scope in organisational transormation: A programme management approach. International Journal of Project Management, 14(6), 331-339.

Linden, G., \& Creighton, P. (2008). The Expo Book: A guide to the planning, organization, design and operation of world expo. Available at www.theexpobook.com

Locatelli, G., \& Mancini, M. (2010). Risk management in a mega-project: The Universal EXPO 2015 case. International Journal of Project Organisation and Management, 2(3), 236-253.

Locatelli, G., \& Mancini, M. (2012). Looking back to see the future: Building nuclear power plants in Europe. Construction Management and Economics, 30(8), 623-637.

Love, P., Holt, G., Shen, L., \& Irani, Z. (2002). Using systems dynamics to better understand change and rework in construction project management systems. International Journal of Project Management, 20(6), 425-436.

Lycett, M., Rassau, A., \& Danson, J. (2004). Programme management: A critical review. International Journal of Project Management, 22(4), 289-299.

Mavrotas, G., Caloghirou, Y., \& Koune, J. (2005). A model on cash flow forecasting and early warning system for multi-project programmes: Application to the Operational Programme fot the Information Society in Greece. International Journal of Project Management, 23(2), 121-133.

Maylor, H. (2004). Project management (3rd ed., pp. 110116). Harlow, UK: Financial Times.

Mazzeo, G. (2008). Great events: Indicators for classification and their impact on the urban system. TeMalab, 1(2), 77-86.

Mills, B., \& Rosentraub, M. S. (2013). Hosting mega-events: A guide to the evaluation of development effects in integrated metropolitan regions. Tourism Management, 34, 238-246.

Moscardo, G. (2007). Analyzing the role of festivals and events in regional development. Event Management, 11(1-2), 23-32. 
Murata, T. (1989). Petri nets: Properties, analysis and applications. Proceedings of the IEEE, 77(4), 541-580.

Nieminen, A., \& Lehtonen, M. (2008). Organisational control in programme teams: An empirical study in change programme context. International Journal of Project Management, 26(1), 63-72.

Office of Government Commerce. (2007). Managing successful programmes. London: The Stationery Office.

Papagiannopoulos, P., Xenikos, D. G., \& Vouddas, P. (2009). Event management and group communications: The case of the 2004 Olympic Games in Athens. Event Management, 13(2), 103-116.

Payne, J., \& Turner, J. (1999). Company wide project management: The planning and control of programmes of projects of different type. International Journal of Project Management, 17(1), 55-59.

Pelleginelli, S., \& Partington, D. (2006). Pitfalls in taking a project-based view of programmes. Madrid: Project Management Institute-Europe, Middle East and Africa.

Preuss, H. (2009). Opportunity costs and efficiency of investments in mega sport events. Journal of Policy Research in Tourism, Leisure and Events, 1(2), 131-140.

Prudnikova, N. (2012). Environmental problems and unintended consequences of the Winter Olympic Games: A case study of Sochi 2014. Journal of Policy Research in Tourism, Leisure and Events, 4(2), 211-214.

Roche, M. (2000). Mega-event and modernity. London: Routledge.

Rodrigues, A., \& Bowers, J. (1996). The role of system dynamics in project management. International Journal of Project Management, 14(4), 213-220.

Ruuska, I., Ahola, T., Artto, K., Locatelli, G., \& Mancini, M. (2011). New governance approach for multi-firm projects: Lessons from Olkiluoto 3 and Flamanville 3 nuclear power plant projects. International Journal of Project Management, 29(6), 647-660.

Shehu, Z., \& Akintoye, A. (2009). Construction programme management theory and practice: Contextual and pragmatic approach. International Journal of Project Management, 27(7), 703-716.

Short, J., \& Kopp, A. (2005). Transport infrastructure: Investment and planning. Policy and research aspects. Transport Policy, 12(4), 360-367.

Silvers, J. R., Bowdin, G. A., O’Toole, W. J., \& Nelson, K. B. (2006). Towards an international event management body of knowledge. Event Management, 9(4), 185-198.

Singh, N., \& Hu, C. (2008). Understanding strategic alignment for destination marketing and the 2004 Athens Olympic Games: Implications from extracted tacit knowledge. Tourism Management, 29(5), 929-939.

Stretton, A. (2010). A multi-project perspective on project management. PM World today, XII (IV), 1-16.

Turner, J. (2009). The handbook of project based management. New York: McGraw-Hill.

Van Marrewijk, A. (2005). Strategies of cooperation: Control and commitment in mega projects.M@n@gement, 8(4), 89-104.

Van Marrewijk, A. (2008). Managing public-private megaprojects: Paradoxes, complexity and project design. International Journal of Project Management, 26(6), 591-600.

Van Wee, B. (2007). Large infrastructure projects: A review of the quality of demand forecast and cost estimations. Environment and Planning B: Planning and Design, 34(4), 611-625. 